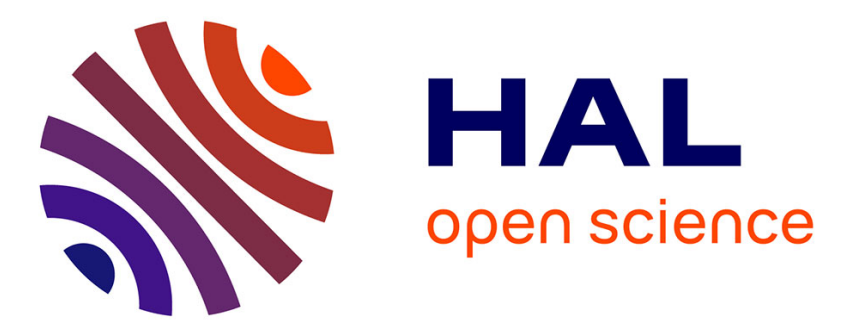

\title{
Thermal analysis in Ti-6Al-4V drilling
}

Ismaïl Lazoglu, Gérard Poulachon, Christophe Ramirez, Mohammad Akmal, Bertrand Marcon, Frédéric Rossi, José Outeiro, Michael Krebs

\section{To cite this version:}

Ismaïl Lazoglu, Gérard Poulachon, Christophe Ramirez, Mohammad Akmal, Bertrand Marcon, et al.. Thermal analysis in Ti-6Al-4V drilling. CIRP Annals - Manufacturing Technology, 2017, pp.1-4. 10.1016/j.cirp.2017.04.020 . hal-01549110

\section{HAL Id: hal-01549110 https://hal.science/hal-01549110}

Submitted on 28 Jun 2017

HAL is a multi-disciplinary open access archive for the deposit and dissemination of scientific research documents, whether they are published or not. The documents may come from teaching and research institutions in France or abroad, or from public or private research centers.
L'archive ouverte pluridisciplinaire HAL, est destinée au dépôt et à la diffusion de documents scientifiques de niveau recherche, publiés ou non, émanant des établissements d'enseignement et de recherche français ou étrangers, des laboratoires publics ou privés. 


\title{
Thermal analysis in Ti-6Al-4V drilling
}

\author{
Ismail Lazoglu (2) $)^{\mathrm{a}, *}$, Gérard Poulachon (2) ${ }^{\mathrm{b}}$, Christophe Ramirez ${ }^{\mathrm{b}}$, Mohammad Akmal ${ }^{\mathrm{a}}$, \\ Bertrand Marcon $^{\mathrm{b}}$, Frédéric Rossi ${ }^{\mathrm{b}}$, José Outeiro $(2)^{\mathrm{b}}$, Michaël Krebs ${ }^{\mathrm{b}}$
}

${ }^{a}$ Koc University, Manufacturing and Automation Research Center, Istanbul, Turkey

${ }^{\mathrm{b}}$ Arts et Metiers ParisTech, LaBoMaP, Cluny, France

\section{A R T I C L E I N F O}

\section{Keywords:}

Drilling

Temperature

Titanium

\begin{abstract}
A B S T R A C T
Ti-6Al-4V is commonly used especially in aerospace and biomedical industries. This alloy is known as a difficult-to-cut material. Due to its poor thermal properties, the heat generated during machining processes traps near material deformation zones. This causes detrimental high temperatures for the cutting tools. This article combines the analytical and FEM modeling techniques to estimate the temperature evolution of carbide tools in Ti-6Al-4V drilling. In this article, a novel thermocouple based temperature measurement setup is also introduced. Moreover, the simulated and measured temperatures under various cutting conditions for the drilling of Ti-6Al-4V are presented for the validation.
\end{abstract}

\section{Introduction}

Several thermal measurement devices dedicated for machining are already available on the market [1]. Out of those apparatus, the infrared CCD camera together with the thermocouple (TC) based techniques are the most well-known and efficient ways to measure the temperature in turning [2,3]. Usually, knowing precisely the cutting temperature is mandatory to understand the thermal phenomena involved in the cutting zone and moreover for simulation's validation purposes [4]. The first studies in drilling were initiated by Rumford [5] and Schmidt and Roubik [6] by using a calorimetric test to determine the heat generation. More recently, Agapiou and Stephenson [7] and Ramirez et al. [8] have used two different devices to measure the temperature during a drilling operation. Respectively, the first one consists of inserting two Ktype thermocouple wires through the lubrication holes close to the cutting edge. The second method converts the tool to an actual thermocouple by positioning in the workpiece an insulated wire. While the cutting edge cuts the wire, it generates a sudden hot junction producing a potential difference and thus, allowing to measure the temperature at that specific position and time.

Since the early 2000, temperature measurements during drilling operations are more and more investigated. Le Coz et al. [9] and Kerrigan et al. [10] performed measurements with thermocouples embedded inside the drill. The data are transferred to the acquisition chain thanks to an on-board wireless system located in the tool holder. Beno and Hulling [11] used a bichromatic pyrometer receiving radiant light through an optical fiber located in the workpiece, in a direction parallel to the drill axis to measure the temperature of the cutting edge. The same kind of experimental set-up has been used by Ueda et al. [12] for alloy steel, cast iron and aluminum alloys machining.

\footnotetext{
* Corresponding author.

E-mail address: ilazoglu@ku.edu.tr (I. Lazoglu).
}

The ability to simulate, analytically or numerically, the physics of the process gives tremendous control toward further improvement and development of new vista. Earlier years produced analytical models for cutting temperatures on simple tool geometries, nevertheless, latter progress in computational sciences, numerical techniques were developed for estimating temperatures on complex tool geometries and processes. Komanduri and Hou [13] used different heat source models to estimate temperature distributions. Lazoglu and Altintas [14] used a finite difference numerical model for predicting temperature distribution in chip and tool for continuous and interrupted machining operations. Later Lazoglu and Islam [15] extended the same approach to oblique machining operations for temperature prediction. The understanding of the thermo-mechanical phenomena was further improved with the introduction of a model for the transient heat partition coefficient between chip and tool rake face by Islam et al. [16].

The present article will describe a newly designed device, named Rotary Tool Temperature (RTT), allowing to measure the drilling temperature close to the cutting edge. This innovative device has the advantage to be easily associated with a rotating multi-component dynamometer for drilling and milling operations. Comparisons in-between experiments and simulations are presented. A semi analytical hybrid approach is adopted for the simulation of temperature fields on the drilling tool. The heat generation source is estimated using the cutting conditions and material mechanical properties, whereas the mechanics of cutting provided the size of heat generation zone from the tool/chip contact length. Finally, finite element analysis was employed to achieve the temperature distribution prediction.

\section{Rotary Tool Temperature device}

Fig. 1 shows the new measurement device, integrated to the rotary dynamometer and tool holder for simultaneously measuring the temperature as well as forces and torques during the 


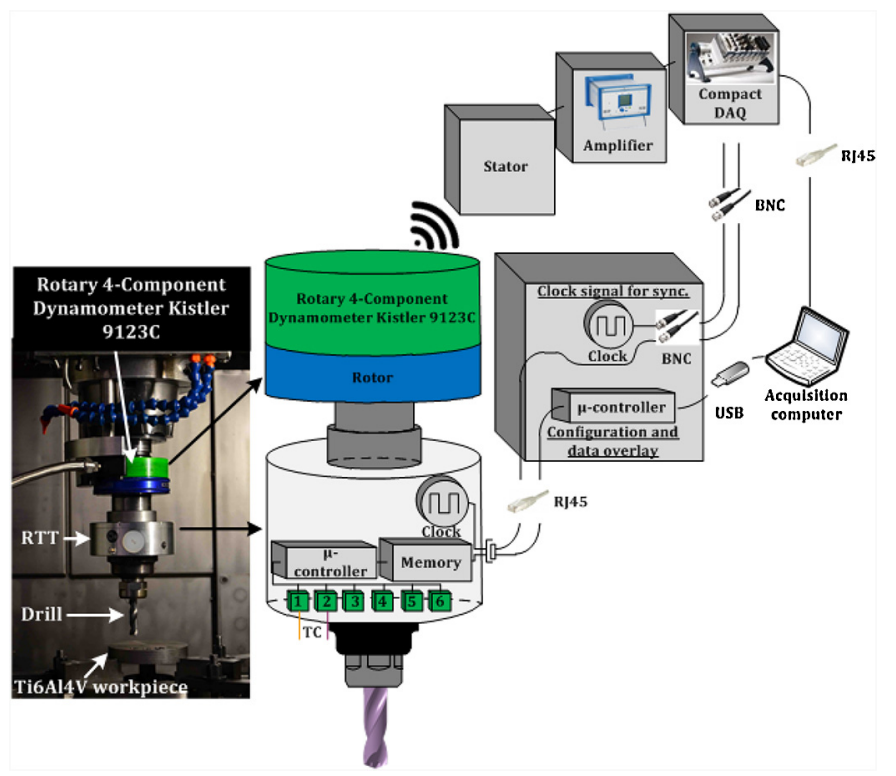

Fig. 1. Experimental setup and scheme of the temperature acquisition.

drilling operations. This RTT device consists of connectors with cold junction compensations to acquire signal up to six thermocouples, an internal memory to store the signal as a function of time during machining, an on-board lithium battery (3.6 V, 3.6 Ah, and a maximum recommended continuous current of $130 \mathrm{~mA}$ ), and an internal clock to synchronize all the signals. The RTT device can be mounted on a standard tool holder to measure the temperature in both drilling and milling operations. The system has two parts: the RTT itself assembled and spinning together with the drill, and an external module in charge of the data communication to the computer thanks to an RJ45 connection. The external module includes an independent clock; this clock pulse is essential when a simultaneous measurement of cutting forces and temperature is necessary.

Indeed, in this peculiar case, it is necessary to synchronize the different signals; to this end, it requires to launch the two clocks with the same pulse rate and triggered simultaneously. When the clock synchronization is complete, the two acquisition systems are unplugged and the machining is performed. The cutting forces and the external clock signal are recorded independently; after which the temperature data are downloaded from the RTT on-board memory and post-synchronized to the other signals. In the present study, the RTT device is used to register signal from two thermocouples. For this purpose, the drill is firstly prepared with
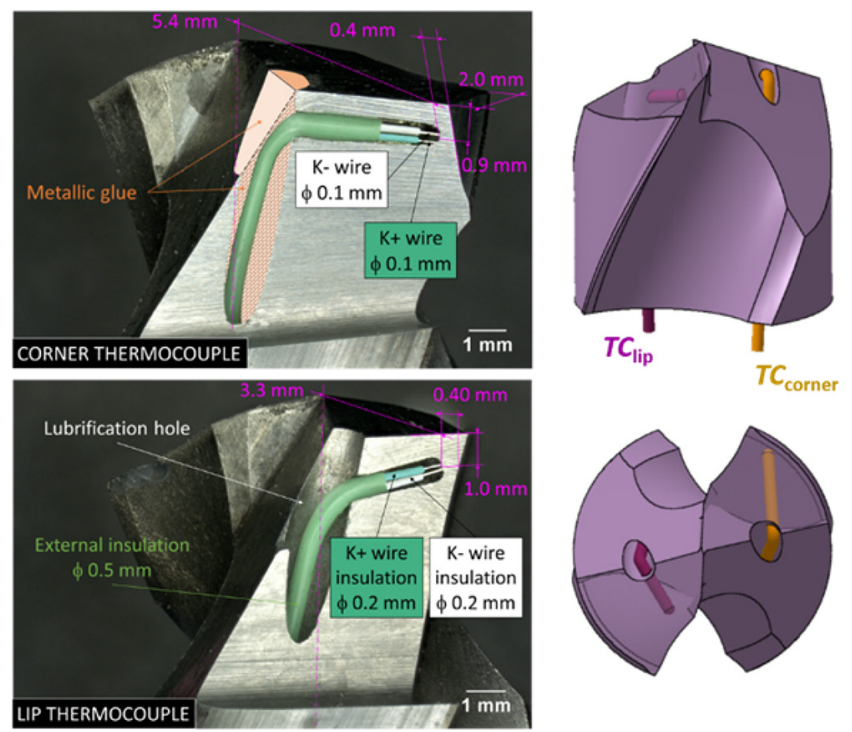

Fig. 2. Illustration of the corner and lip thermocouple locations in the drill. two holes, obtained by electrical discharge machining (EDM), starting from the back of flute to end either close to the drill corner for one side or at the middle of the cutting lip for the other side of the drill; those two temperature locations are labeled as $T C_{\text {corner }}$ and $T C_{\text {lip }}$ respectively. The two thermocouple wires connected to the RTT device are then slipped inside the lubricant canals and inside the previously mentioned EDM holes as shown in Fig. 2.

The two thermocouples are secured to the drill body using two different high temperature ceramic glues: one is charged with silver particles, as a result improving its thermal conductivity and used at the bottom of the EDM hole to connect the two thermocouple wires with the drill body, the other one is used to secure the wires to the drill permanently avoiding any signal disruption when the tool is turning during the machining motion. The main characteristics of the RTT device presented and used in this work are summarized in Table 1 .

Table 1

RTT device specifications.

\begin{tabular}{ll}
\hline Memory capacity & $64 \mathrm{MB}$ \\
Acquisition frequency & Up to $2.25 \mathrm{KHz}$ \\
Accuracy & $0.18 \mathrm{~K}$ \\
Tool-holder & Body of $50 \mathrm{~mm}$ diameter
\end{tabular}

The thermocouples are used in a specific configuration to enable an instantaneous time response. As represented in Fig. 2, the two thermocouple wires are in direct electrical contact with the bottom of the $0.5 \mathrm{~mm}$ diameter hole in the tool. There are two hot junctions: $\mathrm{K}+/ \mathrm{WCC}$ and $\mathrm{WCCo} / \mathrm{K}-$. As the tool material is part of the hot junction, the Seebeck's effect response is instantaneous. The only measurement time delay comes from the data acquisition frequency. The exact location of the measurement is at the $\mathrm{K}+1$ WCCo junction since the electromotive forces generated by the WCCo/K - is close to zero. The RTT calibration was conducted under the FD X07-029-2 standard, and the thermal drift checked and resulted as non-significant until $70^{\circ} \mathrm{C}$ inside the RTT for both temperature measurement and for the clock generator.

\section{Thermal modeling}

Thermal modeling requires the modeling of force field to estimate the heating load for the drilling simulations. The cutting forces for the drilling process were estimated using the discretized orthogonal to oblique transformation model as described by Altintas [17]. The geometry of the helical drill used for the development of the oblique model is shown in Fig. 3.

$$
\left.\begin{array}{l}
d F_{\mathrm{t}}(z)=K_{\mathrm{tc}}(z) d A+\Delta b K_{\mathrm{te}} \\
d F_{\mathrm{f}}(z)=K_{\mathrm{fc}}(z) d A+\Delta b K_{\mathrm{fe}} \\
d F_{\mathrm{r}}(z)=K_{\mathrm{rc}}(z) d A+\Delta b K_{\mathrm{re}}
\end{array}\right\}
$$

$$
h=\frac{c}{2} \sin \kappa_{t}, \quad \Delta b=\frac{\Delta z}{\cos \kappa_{t}}
$$

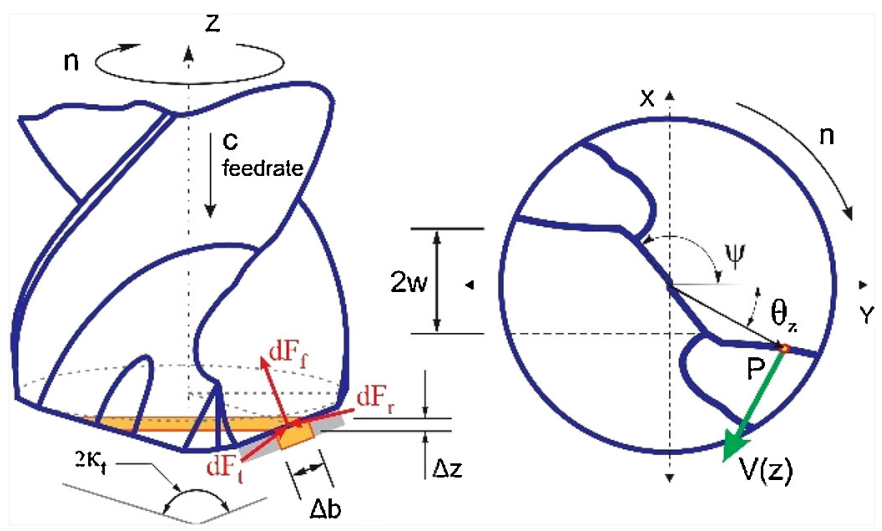

Fig. 3. Discretization of cutting forces along the cutting lip. 
Eq. (1) determines the discrete force components along the tangential $\left(d F_{\mathrm{t}}\right)$, feed $\left(d F_{\mathrm{f}}\right)$ and radial $\left(d F_{\mathrm{r}}\right)$ direction for a selected disk with the differential chip load $(d A)$ of $(\Delta b \cdot h)$. Here, $\left(K_{\mathrm{tc}}, K_{\mathrm{fc}}, K_{\mathrm{rc}}\right)$ and $\left(K_{\mathrm{te}}, K_{\mathrm{fe}}, K_{\mathrm{re}}\right)$ are the cutting force and edge force coefficients for the tangential, feed and radial direction respectively. The cutting coefficients calculated and used to predict the cutting forces for these experiments are provided in Table 2.

Table 2

Cutting coefficients calculated and used to predict the cutting forces during drilling; $K_{\mathrm{te}}$ and $K_{\mathrm{fe}}$ are 24 and $43 \mathrm{~N} \mathrm{~mm}^{-1}$, respectively in all regions.

\begin{tabular}{lllll}
\hline $\begin{array}{l}\text { Cutting force coefficients } \\
{\left[\mathrm{N} \mathrm{mm}^{-2}\right]}\end{array}$ & Region 1 & Region 2 & Region 3 & Region 4 \\
\hline$K_{\mathrm{tc}}$ & 2445 & 2154 & 1953 & 1815 \\
$K_{\mathrm{fc}}$ & 1523 & 1042 & 774 & 606 \\
$K_{\mathrm{rc}}$ & 892 & 649 & 481 & 372 \\
\hline
\end{tabular}

The mechanical properties of the workpiece material required by the transformation model for the cutting forces analytical modeling, and for a $\Delta z$ thick discrete disk (as shown in Fig. 3), were taken from the Ti-6Al-4V alloy material database reproduced in [17]. The analytical calculation of the transition torque required for the selected cutting conditions is in good agreement with the experimentally measured torque as shown in Fig. 4.

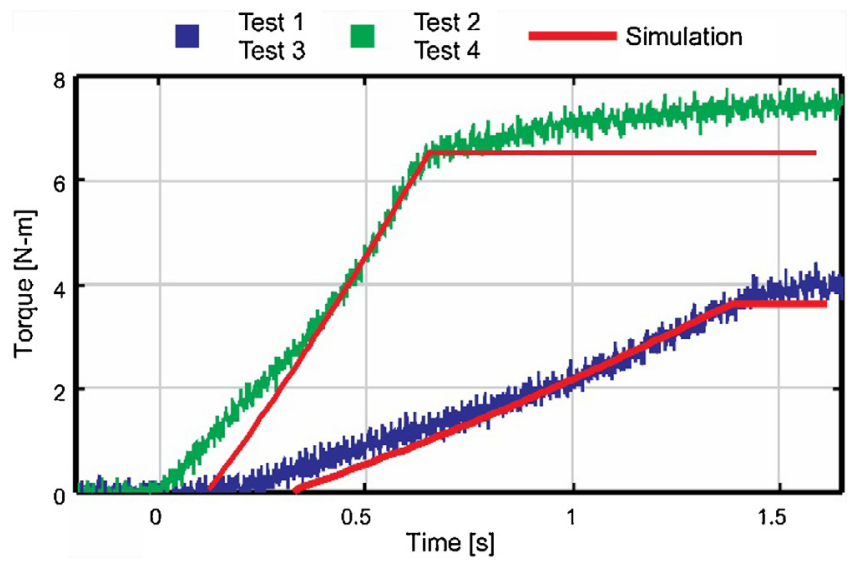

Fig. 4. Torque prediction are compared with the experimental data for the two feedrates.

The experiment drill chisel edge width $w$ and chisel edge angle $\psi$ was $2 \mathrm{~mm}$ and $131^{\circ}$ respectively. The drill geometry is complex and changes along the cutting lip. The critical parameters such as chip flow angle $\eta$, effective rake angle $\alpha_{\mathrm{f}}$, oblique shear angle $\phi_{\mathrm{i}}$, normal shear angle $\phi_{\mathrm{n}}$, local helix angle $\beta_{\mathrm{z}}$ vary and affect the differential cutting forces on the cutting lip. The variation of those angles are illustrated in Fig. 5.

The resultant cutting force $\left(d F_{R}\right)$ on a differential chip load can be determined as the following:

$d F_{\mathrm{R}}(z)=\sqrt{d F_{\mathrm{t}}^{2}(z)+d F_{\mathrm{f}}^{2}(z)+d F_{\mathrm{r}}^{2}(z)}$

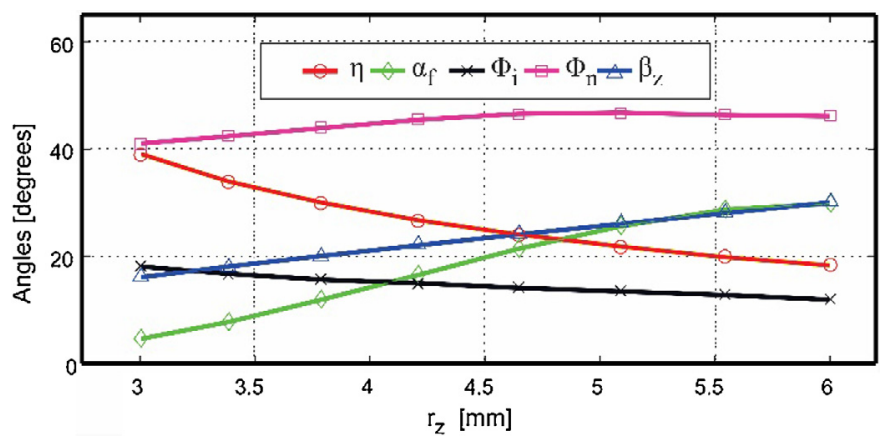

Fig. 5. Variation of angles along the drill cutting lip.
The resultant cutting forces were then dissolved into their friction $\left(d F_{\mathrm{u}}\right)$ and normal components $\left(d F_{\mathrm{v}}\right)$ using the friction angle $\left(\beta_{\mathrm{a}}\right)$ in Eqs. (3) and (4) as follows:

$d F_{\mathrm{u}}(z)=d F_{\mathrm{c}}(z) \sin \left(\beta_{\mathrm{a}}\right)$

$d F_{\mathrm{v}}(z)=d F_{\mathrm{c}}(z) \cos \left(\beta_{a}\right)$

Furthermore, the same parameters were used to establish the chip contact length $l_{\mathrm{c}}$ and chip velocity $V_{\mathrm{c}}$ as described in [15] using Eqs. (5) and (6).

$l_{\mathrm{c}}=\frac{h \cdot \sec \eta \cdot \sin \left(\phi_{n}+\theta_{n}\right)}{\sin \phi_{n} \cdot\left(\cos \alpha_{n} \cos \theta_{n}-\sin \alpha_{n} \sin \theta_{n}\right)}$

$V_{\mathrm{c}}=\frac{V \cdot \sin i(z) \cdot \sin \phi_{n}(z) \cdot \sec \eta(z)}{\tan \phi_{i}(z) \cdot \cos \alpha_{n}(z)+\sin \phi_{n}(z) \cdot \tan \eta(z)}$

The power lost to friction for the discrete section along the cutting edge of the drilling tool is the product of the differential friction force and the instantaneous chip velocity, given by Eq. (7).

$d P_{\mathrm{u}}(z)=d F_{\mathrm{u}} \cdot V_{\mathrm{c}}(z)$

The second step used the information produced in the previous step to define the heating load and area which is active on the drilling tool. The heating load in this case for the tool is the heat partition coefficient corrected sum of all products of the differential friction force and the instantaneous chip velocity for a discrete element along the cutting edge of the drilling tool, calculated using the following equation:

$P_{\mathrm{u}}=\sum d P_{\mathrm{u}}(z) ; \quad P_{\mathrm{f}}=\lambda \cdot P_{\mathrm{u}}$

The heat partition coefficient for the tool $(\lambda)$ was selected as 0.85 and 0.60 corresponding to the two cutting speeds as reported in [18].

Force, torque and temperature measurements were obtained in drilling of Ti-6Al-4V titanium alloy with a $12 \mathrm{~mm}$ diameter and $30^{\circ}$ nominal helix angle, uncoated, two fluted carbide drill in dry cutting conditions as given in Table 3. Drilling depth was kept at $20 \mathrm{~mm}$ in all tests.

Table 3

Cutting speed and feedrate values.

\begin{tabular}{llll}
\hline Test \# & $\begin{array}{l}\text { Rotational } \\
\text { speed }[\mathrm{rpm}]\end{array}$ & $\begin{array}{l}\text { Cutting speed } \\
\left(V_{\mathrm{c}}\right)\left[\mathrm{m} \mathrm{min}^{-1}\right]\end{array}$ & $\begin{array}{l}\text { Feedrate }(f) \\
{\left[\mathrm{mm} \mathrm{rev}^{-1}\right]}\end{array}$ \\
\hline 1 & 266 & 10 & 0.1 \\
2 & 266 & 10 & 0.2 \\
3 & 796 & 30 & 0.1 \\
4 & 796 & 30 & 0.2 \\
\hline
\end{tabular}

The finite elements model (FEM) was developed for blind hole drilling. The tetrahedral type elements were selected to mesh the complex geometry of the tool. The mesh density was variable, but to capture the temperature distribution accurately it was made sure that the heat load areas had very fine mesh. The total number of tetrahedral element was 447,267 with a minimum element size of $2 \mu \mathrm{m}$. The boundary conditions on the tool and workpiece are selected to reflect the experimental conditions closely. Thermodependent thermal conductivity was used for both the workpiece and the drill materials. The cutting process is simulated as a time dependent heat transfer model, where the heat load will remain active for the duration of the cut as it was in the experiment. The heat load, as calculated earlier, is defined to be active only at the tool chip contact zone on the tool (Fig. 6). Comsol Multiphysics software was used for the FEM analysis on an Intel Xeon CPU W5590@ $3.33 \mathrm{GHz}, 8$ cores system for modeling the temperature distribution on the drill bit. Simulation time for each condition was less than $30 \mathrm{~min}$. 


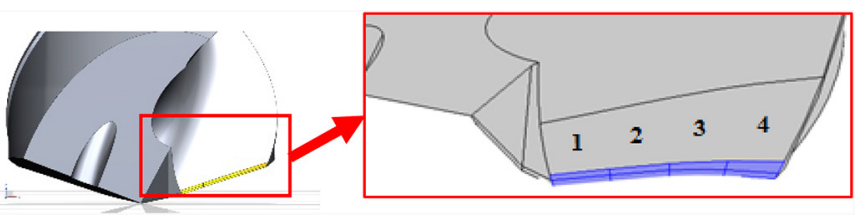

Fig. 6. Chip contact zone divided into four discrete regions for the mechanical and thermal simulations.

\section{Experimental validations}

The drilling tests were performed on a DMC DMG 65 CNC machining center. Tests at each condition were performed three times to verify the repeatability. Only one drill had been used for the whole experimental campaign to avoid dispersion; a previous campaign ensured no tool wear can appear during the tests. Axial force $F_{z}$ and torque $M_{z}$ were also measured by using a rotary type 9123C Kistler dynamometer (Fig. 4). Force and temperature signals were sampled at the frequencies of $2 \mathrm{kHz}$ and $256 \mathrm{~Hz}$, respectively. During the drilling tests, the tool temperature at the two thermocouple locations specified previously were recorded. Simulated and measured tool temperatures at the specified tool corner and tool lip points are presented in Fig. 7. As seen in this figure, the simulation results and experimental measurements with the lip and corner thermocouples are matching quite well in trends as well as amplitudes with less than $10 \%$ differences at the maximum temperature points. For the cutting speed of $10 \mathrm{~m} \mathrm{~min}^{-1}$ and feedrate of $0.1 \mathrm{~mm} \mathrm{rev}^{-1}$, temperature is about $370{ }^{\circ} \mathrm{C}$ at the thermocouple locations. When the cutting speed is increased to $30 \mathrm{~m} \mathrm{~min}^{-1}$ and feedrate of $0.2 \mathrm{~mm} \mathrm{rev}^{-1}$, tool temperature at the thermocouple points are increased to about $500{ }^{\circ} \mathrm{C}$. Simulation results show that the local temperature near the outer corner of the cutting lip, the tool temperature can be even higher as shown in Fig. 8.
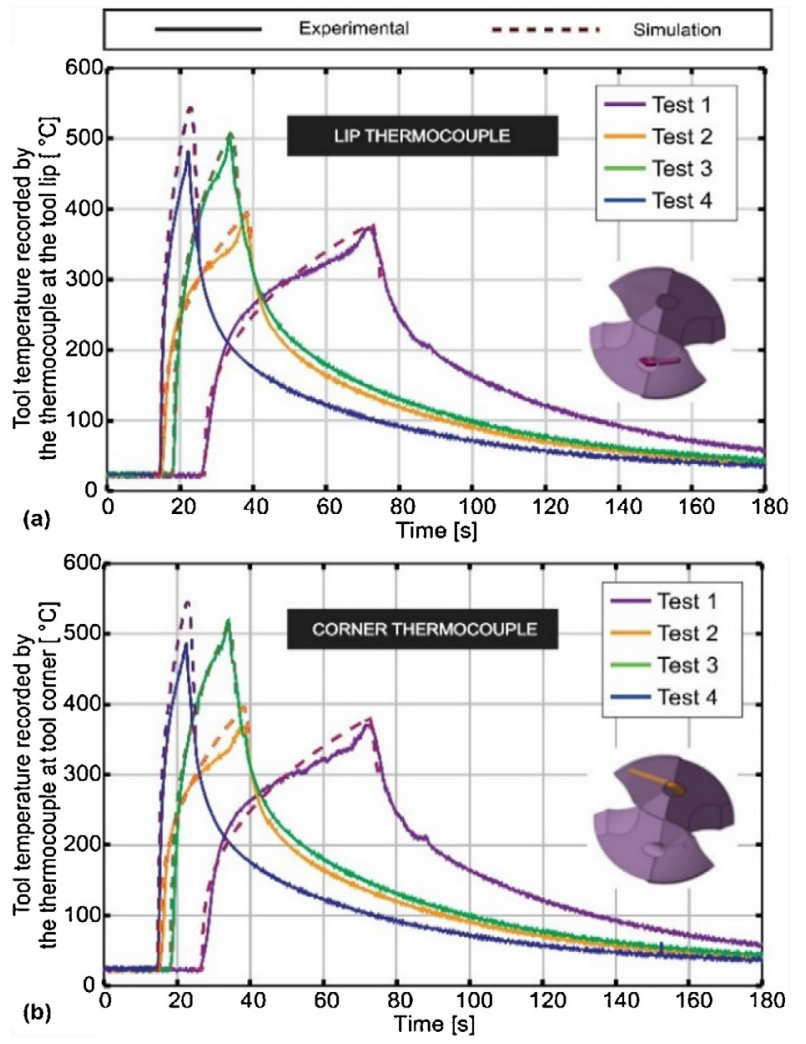

Fig. 7. Simulated and measured tool temperatures: (a) for the thermocouple at the lip point (at $T C_{\text {lip }}$ ) and (b) for the thermocouple at the corner point (at $T C_{\text {corner }}$ ) in the drilling of Ti-6Al-4V under the conditions given in Table 3.

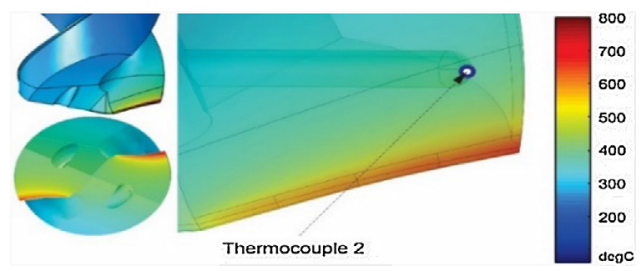

Fig. 8. Temperature distribution on the drill cutting edge and tool body for $V_{\mathrm{C}}=10 \mathrm{~m} \mathrm{~min}^{-1}$ and $f=0.2 \mathrm{~mm} \mathrm{rev}^{-1}$.

\section{Conclusion}

Temperature remains to be one of the major limiting factors toward improving productivity of advanced engineering materials like titanium alloys. Thermal analysis of drilling is critical for better understanding of the process. This article combined the analytical and FEM modeling techniques to estimate the temperature evolution of carbide tools in Ti-6Al-4V drilling. In the article, a new thermocouple based temperature measurement system, named as Rotary Tool Temperature (RTT) device, was introduced. Moreover, the simulated and measured temperatures under various cutting conditions for the drilling of Ti-6Al-4V were presented as validations for the thermal model.

\section{References}

[1] Davies MA, Ueda T, M'Saoubi R, Mullany B, Cooke AL (2007) On the Measurement of Temperature in Material Removal Processes. CIRP Annals - Manufacturing Technology 56(2):581-604.

[2] Kusiak A, Battaglia J-L, Rech J (2005) Tool Coatings Influence on the Heat Transfer in the Tool During Machining. Surface and Coatings Technology 195(1):29-40.

[3] M’Saoubi R, Le Calvez C, Changeux B, Lebrun JL (2002) Thermal and Microstructural Analysis of Orthogonal Cutting of a Low Alloyed Carbon Steel using an Infrared-Charge-Coupled Device Camera Technique. Proceedings of the Institution of Mechanical Engineers Part B Journal of Engineering Manufacture 216(2):153-165

[4] Lazoglu I, Bugdayci B (2014) Thermal Modeling of End Milling. CIRP Annals Manufacturing Technology 63(1):113-116.

[5] Rumford CB (1804) An Inquiry Concerning the Nature of Heat and Its Mode of Communication. Philosophical Transactions of the Royal Society of London 94:77-182.

[6] Schmidt AO, Roubik JR (1949) Distribution of Heat Generated in Drilling. Transactions of ASME 71(3):245-252.

[7] Agapiou JS, Stephenson DA (1994) Analytical and Experimental Studies of Drill Temperatures. Journal of Engineering for Industry 116(1):54

[8] Ramirez C, Poulachon G, Rossi F, M'Saoubi R (2014) Tool Wear Monitoring and Hole Surface Quality During CFRP Drilling. Procedia CIRP 13:163-168.

[9] Le Coz G, Marinescu M, Devillez A, Dudzinski D, Velnom L (2012) Measuring Temperature of Rotating Cutting Tools: Application to MQL Drilling and Dry Milling of Aerospace Alloys. Applied Thermal Engineering 36:434-441.

[10] Kerrigan K, Thil J, Hewison R, O'Donnell GE (2012) An Integrated Telemetric Thermocouple Sensor for Process Monitoring of CFRP Milling Operations. Procedia CIRP 1(1):449-454.

[11] Beno T, Hulling U (2012) Measurement of Cutting Edge Temperature in Drilling. Procedia CIRP 3(1):531-536.

[12] Ueda T, Nozaki R, Hosokawa A (2007) Temperature Measurement of Cutting Edge in Drilling -Effect of Oil Mist. CIRP Annals - Manufacturing Technology 56(1):93-96.

[13] Komanduri R, Hou ZB (2000) Thermal Modeling of the Metal Cutting Process. Part I. Temperature Rise Distribution due to Shear Plane Heat Source. International Journal of Mechanical Sciences 42(9):1715-1752.

[14] Lazoglu I, Altintas Y (2002) Prediction of Tool and Chip Temperature in Continuous and Interrupted Machining. International Journal of Machine Tools and Manufacture 42(9):1011-1022.

[15] Lazoglu I, Islam C (2012) Modeling of 3D Temperature Fields for Oblique Machining. CIRP Annals - Manufacturing Technology 61(1):127-130.

[16] Islam C, Lazoglu I, Altintas Y (2016) A Three-Dimensional Transient Thermal Model for Machining. Journal of Manufacturing Science and Engineering 138(2):21003

[17] Altintas Y (2012) Manufacturing Automation: Metal Cutting Mechanics, Machine Tool Vibrations, and CNC Design, Cambridge University Press.

[18] Rech J, Arrazola PJ, Claudin C, Courbon C, Pusavec F (2013) Characterisation of Friction and Heat Partition Coefficients at the Tool-Work Material Interface in Cutting. CIRP Annals - Manufacturing Technology 62(1):79-82. 